\title{
Antecedentes de la Ley fundamental de la Iglesia
}

El esquema de la Lex Ecclesiae Fundamentalis, que en adelante se denominará LEF, ha tenido comentarios muy variados según las distintas tendencias. La abundante bibliografía de los años 1971 y 1972 está disminuyendo para dar paso a obras serias y de calidad teniéndose diálogos con una crítica constructiva, técnica y serena. Por tratarse de algo nuevo y fundamental, el proyecto ha evolucionado despacio y se está llegando a una especie de Constitución bastante perfecta. La redacción de estas notas está orientada a estudiar los antecedentes y problemática del esquema de la LEF, siguiendo un método histórico-jurídico y la información oficial, para presentar una síntesis de la evolución histórica, contenido y observaciones formuladas a la LEF, como proyecto de una ley orientada hacia el futuro ${ }^{1}$.

La puesta al día del Derecho Canónico y especialmente la elaboración de una LEF es una prueba del dinamismo y de la misión salvífica de la Iglesia, en la que al lado de carismas hay institu-

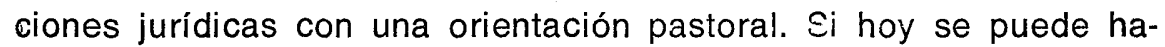
blar de un Derecho natural de contenido variable, mudable o progresivo, conviene destacar que no es posible un inmovilismo canónico, porque es esencial al mismo Derecho una relatividad funcional al compás de la vida y del mundo actual en constante evolución. Hay normas que encierran valores permanentes y estables con proyecciones divinas y dogmáticas, como sería lo establecido por Dios, la tradición y el magisterio eclesiástico al margen de lo contingente y en forma definitiva. Pero al lado del Derecho divino y

1. La información oficial de la Pontificia Commissio Codici Juris Canonici recognoscendo sobre la LEF (Lex Ecclesiae Fundamentalis) ha tdo apareciendo en Communicationes 1 (1969) 29-43 y 114-120; 2 (1970) $82-89$ y $213-216 ; 3$ (1971) $45-46 ; 50-69 ; 169-185$ y $206-212 ; 4$ (1972) 120160, I : 5 (1973) 196-216. 
natural hay leyes fundamentales elaboradas por los hombres, que las pueden modificar al ritmo de las circunstancias. En el Derecho eclesiástico habrá que formular las normas según la nueva doctrina teológica propuesta por la Iglesia.

No es esencial a la Iglesia la formulación de una LEF, sino algo necesario para estructurarse en el momento actual según los delineamientos del Concilio Vaticano II expresados en la Constitución dogmática sobre la Iglesia Lumen gentium. Esta LEF debe contener no sólo los principios pertinentes de Derecho divino, natural y eclesiástico, sino también las costumbres fundamentales de toda la Iglesia para dar unidad orgánica a todo el pueblo de Dios.

\section{ELABORACION DEL PROYECTO DE LEF}

Como se ha llegado ya a una etapa de relativa calma, en la que cada uno puede formular y formarse libre y responsablemente una opinión sobre la LEF, es conveniente exponer las fases del fenómeno histórico, tal como se elaboró el proyecto hasta llegar a su divulgación sin la autorización oportuna, por lo que se creó un clima de hostilidad con una preclusión tendenciosa, que no era favorable ni para una información seria e imparcial, ni para formar una correcta opinión pública.

\section{a) Antecedentes y anuncio de Paulo VI:}

Un optimismo excesivo hizo pensar a no pocos en una pronta revisión del Código de Derecho Canónico, cuando el Papa Juan XXIII anunció la reforma canónica en enero de 1959 dentro de los condicionamientos históricos del Sínodo Romano y la convocación del Concilio Ecuménico. El 28 de marzo de 1963, el mismo Pontífice nombró una Comisión para la revisión del Código de Derecho Canónico, cuyo primer presidente fue el Cardenal Pietro Ciriaci, quien el 6 de mayo de 1965, en el Palazzo dei Convertendi, Sede de la Secretaría de la Comisión, propuso el estudio de varias cuestiones, entre las que se encontraba como primera la de redactar uno o dos Códigos: "Utrum unus an duo Codices faciendi sunt, unus pro Orientalibus et alter pro aliis, praemisso Codice quodam Fundamentali ${ }^{2}$. Según las respuestas dadas, deberían constituirse

2. "Acta Commissionis": Communicationes 1(1969) 36-37. 
otras tantas Comisiones con la anuencia del Papa. En aquel momento actuaba como secretario de la Comisión el jesuita R. Bidagor, auxiliado por un adjunto, Mons. W. Onclin. Para su estudio fue nombrada una comisión preparatoria, en la que fue elegido relator D. Faltin. El veredicto fue favorable a la oportunidad de un Código constitucional o fundamental para toda la Iglesia, contestando al último inciso de la pregunta un poco compleja.

La idea de una LEF, según K. Mörsdorf, surgió como una solución para establecer relaciones canónicas y uniformidad entre la legislación latina y la oriental; si no fue expresada explícitamente en el Concilio Vaticano II, puede ser considerada esta aportación como una de sus consecuencias. La LEF no constituye algo completamente nuevo, porque la Iglesia, desde los primeros siglos posee las Constituciones Apostólicas y una Constitución material, cuyas fuentes son la Escritura, la tradición, algunas leyes y costumbres etc. La novedad estriba en dar forma legal a esa Constitución o Constituciones. Las normas constitucionales son superiores a las normas ordinarias y decretos. Las diferencias existentes entre el Derecho Canónico latino y el oriental se basan en una profunda unidad. La LEF permitiría conjugar la universalidad con la particularidad de las Iglesias, que deben estar relacionadas entre sí mediante una Constitución, que facilitaría las perspectivas ecuménicas y la formación de Derechos particulares adaptados a las necesidades peculiares de cada país. Esto traería, como consecuencias, una reorganización de la Curia, eventual posibilidad de subsumir algunas normas ordinarias para una revisión por tacha de inconstitucionalidad y delimitación administrativa de las funciones del Papa como cabeza de la Iglesia universal y como Patriarca de la Iglesia Latina ${ }^{3}$.

El 20 de noviembre de 1965, en la sala del Consistorio, Paulo VI propuso a la Comisión Pontificia para la revisión del Código, "la

3. K. MORsDorF, "Streiflichter zur Reform des kannonischen Rechts": Archiv für katholisches Kirchenrecht 135 (1966) 46-52. Anteriormente el mismo autor había escrito sobre "Zur Grundlegung des Rechtes der Kirche": Münchener Theologische Zeitschrift 3 (1952) 329348; Cfr. "Zur Neuordnung der Systematik des Codex Juris Canonici": Archiv für katholisches Kirchenrecht 137 (1968) 11-19. La bibliografía hasta julio de 1972 ha sido recogida por J.M. Gonzalez DEL VALLE, "La opinión de los canonistas": El Proyecto de Ley Fundamental de la Iglesia. Redacción Jus Canonicum. (Pamplona 1971) 10-20. 
peculiar cuestión, ciertamente grave de duplicidad de Códigos, uno para la Iglesia latina y otro para la oriental, por lo que sometía a su consideración la oportunidad de redactar un Código común y fundamental para toda la Iglesia" ". Al ser su opinión favorable, pocos días después, el 25 de noviembre, se reunieron los miembros de la Comisión (39 Cardenales y dos Patriarcas), a quienes planteó la conveniencia de elaborar una LEF. La respuesta fue mayoritariamente afirmativa: 27 votaron a favor, seis en contra y los restantes se abstuvieron ${ }^{5}$.

b) Elaboración del proyecto:

Los trabajos de los consultores comenzaron inmediatamente y a los ocho meses de gestación, en los días 26 y 27 de julio de 1966, se presenta el primer esquema o anteproyecto a la consideración del Coetus Centralis: Prima quaedam adumbratio Codicis Ecclesiae fundamentalis, que no estaba bien desarrollado, por lo que el dictamen de los consultores centrales exigió una nueva reelaboración. Entre las observaciones principales, que se le hicieron, figuraba la siguiente: "La LEF debería ofrecer una genuina imagen e idea de la Iglesia de Cristo no sólo jurídica sino también teológicamente". Este principio condicionará en adelante la estructura del proyecto y ocasionará serias dificultades porque, según observaba atinadamente T. García Barberena en el Coloquio HispanoGermano de Canonistas (Salamanca 20 al 23 de enero de 1972), es imposible que la LEF refleje el rostro de la Iglesia, como no es posible que una Constitución estatal proporcione con su lectura una idea genuina o perfecta del país. El Coetus Centralis propuso también otras enmiendas para sintetizar la doctrina del Concilio Vaticano II y ofrecer los principios que regulan las relaciones entre la Iglesia y la sociedad humana. Atendiendo a estos principios y a la naturaleza de la Iglesia con su espíritu ecuménico, se redactó un segundo esquema más detenidamente y se sometió al examen de la Comisión Central, que lo aprobó quoad substantiam con algunas enmiendas durante los días 3 y 4 de abril de $1967^{\circ}$.

Como se requería todavía una revisión total según los criterios

4. AAS 57 (1965) 985-988; Communicationes 1 (1969) 114.

5. Communicationes 3 (1971) 54.

6. Ibid. 1 (1969) 115. 
y las observaciones formuladas por escrito, el 27 de abril de 1967, bajo la nueva presidencia del Cardenal Pericle Felici se constituyó un Coetus specialis de consultores, en su mayor parte canonistas y teólogos de diferentes naciones y tendencias: R. Bidagor, Mons. W. Onclin (relator), Excmo. C. Colombo, K. Mörsdorf, C. Moeller, D. Faltin, W. Bertrams y P. Ciprotti, a los que se unieron posteriormente los Excmos. A. M. Charue, N. Jubany, M. Brini e I. Ziadé, el Rvmo. A. del Portillo y E. Lanne con un auxiliar de estudios: J. Herranz. Sus trabajos en forma de proyecto de LEF fueron presentados por el Cardenal Felici al Sínodo de Obispos reunidos el 3 de octubre de 1967. Fueron mayores las dificultades presentadas que las colaboraciones ofrecidas por los padres sinodales, quienes se pronunciaron en favor de la LEF como Principia quae Codici Juris Canonici recognitionem dirigant ${ }^{\text {? }}$.

En la discusión sinodal se preguntó de nuevo la conveniencia de un Código para la Iglesia latina y oriental o dos Códigos junto con la LEF. Aunque el arzobispo ucraniano de Winnipeg y el Cardenal Patriarca Meouchi se pronunciaron por un Código único para toda la Iglesia, sonó una voz de alarma cuando el arzobispo melquita Edelby expresó su temor ante el peligro de una latinización, incluso en el caso de una LEF y dos Códigos ${ }^{8}$.

Teniendo en cuenta las observaciones formuladas, se reunió el Coetus especial de consultores en los días 28 al 31 de octubre de 1968, 3-7 de marzo y 16-24 de mayo de 1969, dando lugar a un proyecto titulado Schema legis Ecclesiae Fundamentalis cum relatione (sub secreto-reservatum). Lleva fecha de 24 de mayo de 1969 y la firma de $W$. Onclin (como relator). Hay una edición especial del 20 de septiembre de 1969: Textus prior. El día 21 de octubre de 1969 fue presentado a la asamblea extraordinaria del Sínodo Epis-

7. Ibid. 3 (1971) 55; cf. W. ONCLIN, "Relatio super priore schemate Legis Ecclesiae Fundamentalis": Schema Legis Fundamentalis. Textus emendatus cum relatione de ipso Schemate deque emendationibus receptis. (Typis Polyglotis Vaticanis 1971) 60.

8. N. EDELBY, "Faut-il un Code spécial pour les églises orientales": Concilium 28 (1967) 41-49; cf. Herder Korrespondenz 21 (1967) 533; Documentation catholique 66 (1969) 962-963. Para ver la armonía y diferencias entre el Oriente $\mathrm{y}$ el Occidente durante la Edad Media puede verse St. KUTTNER, Harmony from Dissonance. An interpretation of Medievai Canon Law (Latrobe-Pennsylvania 1960); Il codice di diritto canonico nella storia (Roma 1967); A. Garcia Y Garcia, Historia del Derecho Canónico. El Primer Milenio (Salamanca 1967) 159-203. 
copal por el Cardenal Felici, en presencia del Papa, elogiando el trabajo realizado. El día 24 del mismo mes fue repartido el proyecto impreso entre los Cardenales pertenecientes a la Comisión de la reforma del Código y entre los miembros de la Comisión de Teología. La votación de los Cardenales miembros (34 en total) dio el siguiente resultado: 2 placet; 2 non placet y 30 placet juxta modum. La Comisión Teológica Internacional (consultados 30 de los que respondieron 22): 17 placet juxta modum y 5 non placet. Se envió el proyecto también a los miembros de la S. C. para la Doctrina de la Fe, que presentaron solamente enmiendas. Bajo secreto y con las debidas precauciones para evitar una publicación inoportuna llegó a todos los miembros de las distintas Comisiones para la Reforma del Código y a sus colaboradores.

El relator, Mons. W. Onclin, recogió en un volumen todas las observaciones hechas y se las presentó ordenadas sistemáticamente a los consultores del Coetus specialis los días 19-23 de mayo y 20-25 de julio de 1970 con la participación de algunos miembros de la Secretaría para la unión de los cristianos y observadores de comunidades cristianas no católicas. El tercer proyecto, que en la práctica se puede considerar como anteproyecto, Textus prior, corregido y un poco aumentado según las observaciones formuladas, dió lugar a un cuarto proyecto: Textus emendatus cum relatione de ipso schemate deque emendationibus receptis de la LEF (25 de julio de 1970). Una vez impreso fue enviado a todos los obispos con carta del 10 de febrero de 1971 para que estudiasen el esquema LEF con ayuda de peritos y respondiesen personalmente o conjuntamente con su Conferencia Episcopal o Sínodo Patriarcal a las siguientes preguntas: 1." "Si se juzga oportuna una LEF para toda la Iglesia Católica, que sea como fundamento teológico y jurídico de las diversas leyes eclesiásticas. La respuesta sea afirmativa o negativa, con los argumentos pertinentes. 2. ${ }^{a}$ En caso afirmativo, qué propuestas de enmienda deseas hacer: generales a todo el es" quema o al cap. I, II ó III; particulares a cada uno de los cánones" ".

El mismo proyecto fue enviado también a la Unión de Superiores Generales el 9 de marzo de 1971 y a otras entidades religiosas. Las respuesias clara y precisamente redactadas debian ser remiti

9. Communicationes 3 (1971) 45-46. 
das antes del 1 de septiembre del mismo año a la Sede de la Comisión (Via dell'Erba n. 1, 00193 Roma).

Dada la complejidad de la primera pregunta, que habla de fundamento jurídico y fundamento teológico, cuando en realidad son cuestiones diversas, las respuestas no podían ser concretas ni claras. A esto se añade el hecho de que algunas Conferencias Episcopales enviaron la respuesta colectivamente sin precisar los votos y su modalidad. Según el informe del Cardenal Felici a los Padres Sinodales el 3 de noviembre de 1971, hasta el 28 de octubre del mismo año habían respondido 1313 obispos. A la primera pregunta: Si se juzga oportuna una LEF etc. Respuestas: 593 placet; 462 placet juxta modum; 251 non placet. Algunos obispos no han contestado y otros, unos 30 , según se desprende de los informes, respondieron que no se encontraban en condiciones de emitir un juicio sobre la cuestión, ni tenían peritos para asesorarse. La segunda pregunta, videlicet utrum placeat schema "Legis Fundamentalis", uti iacet, an contra animadversiones habeantur de textu emendando, non omnes sententiam dederunt explicitam, sed ad mentem eorum, haec responsa habentur: 61 placet;798 placet juxta modum; 422 non placet. Estos resultados no eran definitivos y en el Sínodo de Obispos el 3 de noviembre se abrió un diálogo de altura en el que emitieron públicamente sus opiniones y preguntas con franqueza los Cardenales J. Parecattil, J.L. Suenens, A. Poma, F. König,Th. B. Cooray, J. Höffner, V. Gracias, J. Landázuri Ricketts y P. Felici; Mons. B. Echeverría Ruiz, Mons. J. Gran, Mons. J.F. Torres Oliver, P. I. Lécuyer, P.T. Van Asten, Mons. A. Farah, y P.A. Fernández, a los que contestaron con gran precisión y cordia'idad el Card. Felici, Mons. Onclin y P. Bidagor, por lo que fueron efusivamente aplaudidos. El periódico L' Osservatore Romano del día 7 de noviembre del mismo año publicó un resumen de las intervenciones, que luego han sido reproducidas en Communicationes. Los Padres sinodales dieron luz verde al proyecto de la LEF para que se siguiese perfeccionando ${ }^{10}$.

c) Divulgación del proyecto:

Antes de que se autorizase su divulgación para el público y cuando aún circulaba en secreto el Textus pricr de la LEF, se dio

10. Ibid. 3 (1971) 169-177; cf. L'Osservatore Romano, 4 de noviempre (1971) 3. 
el lamentable e inesperado fenómeno de su publicación en una revista italiana con una eclosión o aborto ante la opinión publi: ca. Luego apareció también el "Textus emendatus" de la LEF". A partir del mes de Julio de 1971 surge una candente polémica en torno al proyecto de la LEF, que atrajo la atención de la prensa al conocerse la violenta crítica a la LEF firmada por doscientos veinte teólogos centroeuropeos de talla, entre cuyos nombres aparecian K. Rhaner, H. Küng, D.M. Chenu, G. Alberigo y otros de elevado coturno teológico, pero bastante descalzos jurídicamente, creando artificiosamente un clima contrario, no ya al proyecto actual, sino a la idea misma de la LEF. El mismo Cadenal Felici, at informar a los Padres sinodales en noviembre de 1971 sobre el esquema y lo ocurrido, manifestó que bastantes hechos se habian tergiversado por grupos contrarios no ya al proyecto, sino a la misma existencia de una LEF, por lo que se deformó la opinión pública $y_{\text {s }}$ en vez de divulgar el contenido de la LEF y sus antecedentes, se difundian ideas prefabricadas, críticas mordaces y caricaturas ingeniosas, difícilmente asimilables por los católicos de mediana formación ocupados en sus trabajos y deberes familiares.

Algunos juristas y miembros del Coetus de Roma se vieron scrprendidos por las informaciones de la prensa y por la intervención de varios teólogos notables y progresistas, que conservaban del Derecho Canónico una noción atrasada, tal como la habian aprendido en sus años de estudios académicos, y presentaban al Derecho como un fantasma o haz de leyes, y no como organización de conducta y algo necesario a toda sociedad organizada. Desconocían los nuevos conceptos de relación jurídica, pacto, alianza, diferencias entre Derecho público y privado, obligación, norma hipotética etc. Aunque un poco tarde Mons. Onclin y alguros cznsultores del Coetus especial iniciaron una labor encomiable suministrando información oportuna a la prensa sin perjuicio de la publicación oficial y más técnica que iba apareciendo en Communicationes.

En España apareció en noviembre de 1971 un buen aporte científico por parte de la Redación de Jus Canonicum, que en el plazo de 25 días presentó El Proyecto de Ley Fundamental de la

11. Il Regno (Revista quincenal, que se publica en Bolonia). Textus prior 10 ae jullo ( $1 y^{\prime}(U)$ 284-300. El Textus emendatus apareci6 el 15 de marzo (1971) entre "Documentazione", cf. "Appunti per un'analisi criti- 
Iglesia. Texto bilingüe y análisis crítico, donde aparece la opinión de un grupo calificado de canonistas de la Universidad de Navarra (Pamplona) ${ }^{12}$.

Vida Nueva, semanario de información general y religiosa, editado por Propaganda Popular Católica, dedicó un número especial, el 3 de julio de 1971 a la LEF, texto íntegro en castellano y sin notas, aunque con alguna glosa. Hay caricaturas con cierta gracia y buen humor; pero poco apropiadas para crear una opinión pública favorable a la LEF.

Algunas revistas dedicaron diversos arículos, donde serpean no pocas críticas adversas de sacerdotes disidentes para protestar contra todo lo que Ilaman juridicismo y autoritarismo en la Iglesia. No faltaron grupos de contestatarios con críticas oportunas y pertinentes, hechas incluso con buena voluntad; pero otros llegaron a la rebeldía y a la subversión tan lamentada por el mismo Romano Pontífice: "Subversión no sólo de lo que puede y debe ser mejorado en la Iglesia, sino de los mismos fundamentos, de su constitución, de la visión sobrenatural de su ordenamiento, de su disciplina etc." ${ }^{13}$. Roma pedía calma y cordura. La mayoría de los canonistas guardaron silencio prudente, aunque conocían el proyecto divulgado en varios idiomas y por revistas de todo tipo sin la autorización oficial. Era necesario disipar equívocos, por lo que pronto comenzaron a tenerse reuniones y mesas redondas de interés como la celebrada en la Universidad de Macerata los días 12 y 13 de octubre de 1971. Hubo también un simposio en Pamplona Al año siguiente, en Salamanca, bajo la dirección del Instituto San

*a dello Schema di Lex Ecclesiae Fundamentalis", Istituto per le Scienze Religiose Bologna (Via S. Vitale 114-Bologna): Legge e Vangelo (Brescia 1972) 661; R. LAURENTIN, Bilan du Synode (París 1972); G. CAPRILE, "Il pro" getto di Legge fondamentale della chiesa".: Civiltà Cattolica 122 (1971) 288-293; V. PERI, "Il progetto di una LEF": Rivista di storia e letteratura religiosa 7 (1971) 201-210.

12. J. M. GONZALEZ DEL VALLE, P. J. ViladRrCh, J. ARIAS y otros miems sros de la Redacción Jus Canonicum, El Proyecto de LEF... 23-59. Cf. Vi da Nueva 789 (1971) 955-974, va como introducción al Textus emendatus en castellano, una traducción del artículo de G. ALBERIgo, "Una costitu. zione per la chiesa?": Humanitas 26 (1971) 317-329; Orientierung, 35 (1971) 85-90.

13. L'Osservatore Romano 7 y 15 de julio de 1971 , cf. Communicationes 3 (1971) 210-212. La protesta de más de doscientos teólogos puede verse en Testimonianze 14 (1971) 238-239; Y. CoNGAR, "Idée et difficultés d'une Loi fondamentale de l'Eglise": La croix 16 agosto 1971; A. RAuscheR, "Streit um Demokratie": Rheinischer Merkur 10 sept. (1971) 10. 
Raimundo de Peñafort de Derecho Canónico y la colaboración del Instituto Canónico de la Universidad de Munich, se celebró del 20 al 23 de enero, otro simposio (al que ya hice referencia anteriormente): Coloquio Hispano-Germano de Canonistas sobre el proyecto de la LEF. Tuve la oportunidad de asistir a las ponencias y coloquios interesantes, suscitados por las lecciones magistrales de K. Mörsdorf sobre "Introducción general al tema del Coloquio", L. Scheffczyk "problemas eclesiológicos que plantea el proyecto", T. Garcia Barberena sobre "Quaestiones quae in colloquio disceptandae proponuntur" en latín, con tanta propiedad y armonía, que hacía recordar los tiempos de otro profesor salmantino Fray Luis de León; el P. J. Giménez y Martínez de Carvajal "Los derechos de los fieles en el proyecto LEF"; E. Corecco sobre "Los órganos de gobierno"; y clausuró el Coloquio L. de Echeverría y Martínez de Marigorta haciendo un resumen y presentando conclusiones con una prosa jurídica rebosante de cultura, de sabor clásico y gracia nueva, que gana el ánimo y despierta admiración. Este coloquio, celebrado casi a puerta cerrada y con un número limitado de asistentes invitados, llegó a conclusiones positivas en favor de la LEF aportando valiosas contribuciones y sugerencias. En el transcurso del diálogo se propusieron algunas correcciones, incluso un miembro del Instituto de Derecho Canónico de Munich anunció la publicación de un proyecto de LEF en lengua latina que serviria en la revista Archiv für katholisches Kirchenrecht de contrapropuesta al que la Comisión distribuyó entre los obispos ${ }^{14}$.

En Alemania, la revista Herder Korrespondenz de juinio de 1970 publicó una traducción germánica del Textus prior con una informacién documentada sobre la evolución del mismo. Un grupo de profesores de la Universidad de Heidelberg, bajo la dirección de Hans Dombois, perteneciente a la Iglesia luterana, ha colaborado en el perfeccionamiento y divulgación del proyecto de la LEF elaborando los siguientes documentos: $1 .^{\circ}$ Proposiciones a la primera redacción de la LEF (1968). 2. ${ }^{\circ}$ Proposiciones al esquema de la LEF con argumentos corespondientes. $3 .^{\circ}$ Proposiciones diversas al Textus emendatus con un orden sistemático según el orden de

14. L. DE Echeverria, "Coloquio Germano-Español sobre el Proyecto גe LEF": Revista Española de Derecho Canonice 28 (1972) 226. 
los capítulos y cánones del proyecto remitido en latín del Coetus de Roma ${ }^{15}$.

En Francia, Le Monde, que había informado el 22 de abril de 1970 y 2 de abril de 1971 sobre la evolución del proyecto de LEF, publicó un extracto del Textus prior con referencia al Textus emendatus. En habla inglesa, The Tablet del 18 de abril de 1970 reprodujo parte del Textus prior, que había sido publicado el 10 del mismo mes y año por la National Catholic Reporter de Kansas City. Esta publicación está relacionada con el simposio de tres días de duración celebrado bajo la dirección de la Canon Law of America y la colaboración de la Universidad de Fordham en Douglaston, Long Island. Con ocasión de este simposio, el 7 de abril de 1970, Mons. Vallainc, director de la Sala de Prensa de la Santa Sede, declaró que el proyecto era aún secreto y no había sido enviado a los obispos, porque aún estaba en fase de elaboración. Esto era cierto, pues hasta el 10 de febrero de 1971 no fue enviado un volumen con el Textus prior de fecha 24 mayo 1969 y el Textus emendatus del 30 de noviembre de 1970 en secreto. Sin embargo se trataba de un secreto a voces. En Canadá fue divulgado en forma manuscrita y multigrafiada por Germán Lasage con el título: Lex Ecclesiae Fundamentalis, Nature générale du document en $1971^{16}$.

La mayor divulgación de la LEF ha tenido lugar en Italia, de donde ha salido en revistas y estudios especiales para las diferentes partes del mundo. Un estudio voluminoso ha sido elaborado por el Istituto per he Scienze Religiose de Bolonia, ciudad de recio abolengo canonista, recogiendo artículos de fondo en su mayoría contrarios a la LEF, junto con el Textus prior, Textus emendatus y un dossier riservato denominado Appunti per un analisi

15. H. Domвors, Begründung aum Gegenentwurf einer LEF, Fasciculo multigrafiado (Heidelberg 1971); Legis Fundamentalis Ecclesiae, Schema iterum revisum, propositum pro colledio peritorum Heidelbergae (Fascículo también multigrafiado en 1971). Estos y algunos otros de los documentos han sido reproducidos por P. WEBER, "De LEF studio a coetu Peritorum Helldelbergensi Johanne Dombois duce instituto": Periodica de re morali, canonica, liturgica 62 (1973) 423-466; cf. H. DомвоIs, "Sobre la estructura de una LEF": Concilium 48 (1969) 204-211.

16. J.P. J. O'HEARN, "The LEF from a Common Law Viewpoint": Studia Canonica 5 (1971) 208; El Centro de Estudios Medievales de la Universidad de Toronto, especialmente el Pontifical Institute for Medieval Studies de Toronto con los Prof. L. K. Shook y R. W. Crooker han colaborado para un estudio lingüístico $\mathrm{y}$ analítico de la LEF; cf. F. GIUSBERTI, "Analisi del linguaggio teologico della LEF": Leg. e Vang. 344. 
critica dello Schema di LEF ${ }^{17}$. Este dossier ha sido la fuente de muchos artículos de prensa contrarios a la LEF.

Para completar esta rápida reseña sobre la divulgación del proyecto, que no pretende ni puede ser exhaustiva, conviene tener en cuenta que la información oficialmente autorizada en esta materia aparece en Communicationes de la Comisión Pontificia para la Reforma del Código. Este órgano informativo no ha publicado aún el proyecto de LEF, porque sigue hasta la fecha en fase de revisión. Han aparecido los detalles sobre el itinerario de la LEF, algunas fuentes documentales y una relación de las observaciones hechas al proyecto tanto favorables como adversas propuestas por los obispos y examinadas por el Coetus specialis en los días 20 al 24 de noviembre de $1972{ }^{18}$.

Aunque la divulgación de la LEF, sin la autorización oficial, ha ocasionado comentarios contradictorios y tendenciosos, creando un clima de confusión, hay que reconocer que en parte ha sido beneficiosa, porque así se ha oido un poco la voz del pueblo de Dios. Hoy la revisión de la legislación canónica, por más que quiera hacerse en secreto, en el fondo tal secreto es relativo, porque debe hacerse con una basta consulta a las Conferencias Episcopales y a los obispos, quienes a su vez se asesoran tanto por sacerdotes como por laicos y "estos, según su ciencia, competencia y prestigio, tienen el derecho y, en algún caso, la obligación de manifestar su parecer sobre aquellas cosas, que dicen relación al bien de la Iglesia" ${ }^{19}$.

Tanto la exposición del Derecho Canónico, como la LEF, ha de hacerse "mirando al Misterio de la Iglesia según la Constitu-

17. El "dossier riservato: Appunti per un'anal"... fue multigrafiado en abril de 1971 junto con un artículo de G. Alberigo y otro de P. G. CAMAIAMI en italiano, inglés, francés, alemán y español por el "Istituto per le Scienze Religiose" que ha sido reproducido en Legge $e$ Van... 659-696. Se hicieron eco de la polémica y discusión sobre la LEF autores y revistas serias como J. BEYER, "Discussione sulla LEF": La Rivista del clero italiano 51 (1971) 36-41; B. GHERARDINI, "La chiesa e la sua legge": Apollinaris 44 (1971) 630-658; W. Bertrams, "De praemissis et principiis LEF": Periodica de re morali, canonica, liturgica 60 (1971) 511-547; D. Composta, "Il diritto della Chiesa. Alla ricerca delle componendi giuridiche specifiche": Salesianum 34 (1972) 255-294; A. Rava, "Un pontificato, un concilio, una costituzione: da Giovanni XXIII al progetto della LEF": Studi Senesi 84, (1972) 44-137.

18. Communicationes 4 (1972) 120-160.

19. Conc. Vatic. II, Const. dogm. Lumen gentium n. 37. 
ción dogmática Lumen gentium" ${ }^{20}$. Esto responde a una nueva orientación eclesiológica, que va cristalizando en el actual proyecto de la LEF, según los principios del Nuevo Testamento, del Concilio Vaticano II y la naturaleza jurídica de un cuerpo legal. Marginamos por ahora las diversas críticas a la LEF, que veremos después de examinar el contenido del proyecto en sus delineamienios generales.

\section{CONTENIDO DEL ESQUEMA DE LA LEF}

Aparece en primer lugar el proemio o introducción con una formulación concisa y quizás un poco empobrecida de los fundamentos teológicos, que sirven de base constitucional. Dada la importancia, brevedad y valor de su contenido cristológico y orientador se transcribe a continuación el proemio: "El eterno Padre, que envió al mundo a su Hijo Unigénito, Jesucristo, para salvar a los nombres del pecado, santificarlos indefinidamente por la efusión del Espíritu Santo y conducirlos a la gloria dei reino de los cielos, a los creyentes en Cristo, nacidos no de la carne, sino del agua y del Espíritu Santo (Cf. Jn 3,5-6), determinó convocarlos a la Santa Iglesia que fuera para El linaje escogido, sacerdocio real, nación santa, pueblo adquirido... que un tiempo no era pueblo, pero ahora es pueblo de Dios (Pt 2,,9-10)".

"Cristo, pues, que quiso que su Iglesia Santa fuese una comunidad de fe, de esperanza y de caridad, la constituyó asimismo en este mundo como sociedad dótada de órganos jerérquicos y la encargó que perpetuara a través de los tiempos la misión que El recibió del Padre y fuese en El y por el Espíritu Santo como sacramento o signo e instrumento de la unión íntima con Dios y de la unidad de todo el género humano" ${ }^{21}$.

20. Conc. Vatic. II, Decr. Opt. totius n. 16. La influencia del Concilio Vaticano II en el proyecto LEF ha sido reconocida por la mayoria de los comentaristas: F. Grusberti, "Anal. del ling." 341-481; R. SobaNSKI, "La LEF. Quelques réflexions": Nouvelle Revue Théologique 104 (1972) 251-268; F. ZANCHINI DI CASTIGLIONCHIo, "Ancora sulla LEF: alcune osservazioni sul principio quod omnes tangit, ab omnibus probari debet": Il Tetto 9 (1972) 225-229; I. HERRANz, "De principio legalitatis in exercitio potestatis ecclesiasticae": Acta Conventus Internationalis Canonistarum (Typis Polyglottis Vaticanis 1970) 221-238.

21. Cf. Conc. Vatic. II, Const. dogm. Lumen gentium nn. 1,2,4,8 y 9; Paulo VI "Solemnis Professio Fidei, 30 de junio de 1968", n. 19: AAS 60 (1968) 440. 
"Fundada sobre esta divina institución, revelada a través del Evangelio, la Iglesia cumple su misión recibida de Cristo: la cumple cuando salvaguarda con sus leyes la unidad de la fe y detiene y conserva incólume la constitución, que le fue dada por Dios, y ayuda las acciones de los fieles dirigiéndolos a la consecución de la salvación; la cumple también cuando procura que, salvada la unidad de la fe y su constitución divina y única, se desarrollen y fortalezcan aquellas diversidades, que vengan aconsejadas por las circunstancias de lugar y tiempo" 22

Ya en la introducción hay varias citas de la Sagrada Escritura, del Concilio Vaticano II y del Magisterio de la Iglesia lo mismo que en todo el texto de la LEF. Se mezclan elementos teológicos y jurídicos porque la Iglesia, además de institución jurídica, es cuerpo místico y debe salvaguardar elementos humanos, carismáticos y sobrenaturales.

Aunque es difícil hacer un resumen del proyecto, muy denso en su contenido, por lo que se recomienda su lectura reposada, vamos a entresacar algunos conceptos y cánones considerados como más relevantes, más criticables y vertebradores de la LEF.

\section{a) CAP. I: DE LA IGLESIA O DEL PUEBLO DE DIOS}

tructura de la Iglesia ajustándose a la alianza divina entre Dios y su pueblo. En los cc. 1 y 2 se habla del nuevo pueblo de Dios utilizando citas bíblicas y textos del Concilio Vaticano II, especialmente de la Constitución Lumen gentium y del Decreto Unitatis redintegratio. La unidad y multiplicidad de la Iglesia muestran la diversidad del pueblo de Dios vinculado por la caridad y la Eucaristía. La LEF tiene como fin la salus animarum: la salvación de los fieles que se realiza mediante la palabra y los sacramentos. Para cumplir con su misión, la Iglesia necesita estar en constante renovación y en perenne reforma de sí misma.

Artículo 1.: De todos los fieles en general.

En los cc. 3-25 se trata de los derechos y obligaciones de los fieles. "La Iglesia reconoce y proclama la dignidad de la persona hu-

22. Conc. Vat. II, Const. dogm. Lumen gentium n. 23. 
mana; que corresponde a todos y a cada uno de los hombres, puesto que son creados a imagen de Dios; asimismo reconoce los derechos y deberes que de ella dimanan y los protege en razón de la vocación de todos los hombres a la salvación (c. 3). Estas ideas se desarrollan y complementan mejor en el c. 4, donde se dice: "todos los hombres son llamados a formar parte de la Iglesia, puesto que todos están ordenados universalmente al pueblo de Dios y están llamados por la gracia de Dios a la salvación". "Todos los hombres, que conozcan la verdadera Iglesia, están obligados por la misma ley divina a entrar en ella" (c.5). Aunque se habla de la ley divina no se precisa su alcance. En los cc. 6 al 9 se expone la condición de miembro de la Iglesia, a la que solamente pertenecen los bautizados. A partir del c. 10 se especifican los derechos de los fieles, que en la práctica están bastante bien delimitados, quizás para evitar abusos en el ejercicio de los mismos: "verdadera igualdad entre los fieles sin que exista desigualdad alguna por razón de raza o nación, de condición social o sexo" (c. 10); vocación a la santidad (c. 11); derechos al apostolado personal (c. 12); deber de obediencia, derecho a manifestar sus necesidades y deseos a los pastores, derecho y deber de opinar con la debida reverencia a los pastores (c. 13); derecho a los bienes espirituales (c. 14); al propio rito y a la espiritualidad propia (c. 15); derecho de asociación y reunión (c.16); derecho a promover empresas apostólicas (c. 17); a la instrucción y formación cristiana (c. 18); ejercicio de los derechos fundamentales (c. 19); derecho a la seguridad jurídica (c. 20); "nadie puede ser castigado sino en los casos señalados por la ley y según el modo determinado por la misma" (c. 21); derecho a elegir libremente estado de vida (c. 22); derecho a la buena fama (c. 23); a la educación cristiana (c. 24); el deber de ayudar a las necesidades de la Iglesia (c. 25). Hay diversidad entre los fieles por razón de su estado (c. 26); y diversidad de ministerios sagrados por institución divina (cc. 27-28); diversidad de formas de vida solitaria y comunitaria entre los que profesan los consejos evangélicos (c. 29). Los fieles laicos participan también en la misión salvífica y deben ser consultados por los pastores en los asuntos de la lglesia pertinentes a su condición (c. 30 ). No hay ciertamente una taxativa y ordenada declaración de los derechos del hombre; pero estamos en presencia de una temática rica e importante en la que se desarrolla y comparte el dinamismo funcional del Derecho Internacional Público y Privado. Quedan todavía algunos derechos sin 
proteger, como se verá en las críticas y objeciones, que se hacen a este artículo ${ }^{23}$.

\section{Artículo 2.: $\quad$ La Jerarquía de la Iglesia}

En los cc. 31-33 se trata de la jerarquía de la Iglesia en general. Para dirigir al pueblo de Dios, Cristo instituyó ministerios. Quiso que los apóstoles fueran pastores de su Iglesia y puso al frente de ellos a Pedro, cuyo sucesor es el Romano Pontífice. Sucesores de los apóstoles son los obispos, que "ejercen sus funciones en la Iglesia con la cooperación de los presbíteros y diáconos, y con la ayuda también de otros ministros establecidos por el Derecho eclesiástico y de los fieles laicos según las normas de los sagrados canónes (c. 33).

Parágrafo $1 .^{\circ}$ del Sumo Pontifice (cc. 34 - 36).

Tanto la hierarchia ordinis como la hierarchia jurisdictionis confluyen en la persona del Romano Pontífice asistido especialmente por el Colegio Cardenalicio, como senado del Papa, y por el Sínodo de Obispos. En el proyecto se reconoce la doctrina tradicional y conciliar sin hacerse eco hasta la fecha de algunas aportanes posiconciliares sobre la moderna técnica de organización administrativa. La potestad del Papa es ilimitada y contra sus sentencias no cabe apelación. Se establecen algunas normas generales sobre la elección del Vicario de Cristo, potestad y ejercicio de su primacía. Sigue apareciendo la figura del Papa con su potestad plena en un primer plano y como eje central de la jerarquía eclesiástica ${ }^{24}$.

Parágrafo 2. De los obispos (cc. 37-48).

Estos cánones versan sobre los obispos, como sucesores de los apóstoles, que junto con el Romano Pontífice constitu-

23. Cf. P. J. VILADRICH, Teoría de los derechos fundamentales del fiel. Presupuestos críticos (Pamplona 1969) 57-73. Conc. Vat. II, Decl. Dignitatis humanae nn. 1,2,14; Const. dogm. Lumen gentium nn. 7,12,18,31, 33,37,44-46; Const. past. Gaudium et spes nn. 26,29 y 52.

24. Cf. J. Hervada, "Estructura y principios constitucionales del gobierno central": Jus Canonicum 22 (1971) 11-54; Cf. Conc. Vat. I Const. Pastor aeternus: DENz. nn. 1826-1827; Conc. Vat. II, Const. dogm. Lumen gentium. nn. 22 y 27; Decr. Christus Dominus nn. 2 y 9; BoNIFACIo VIII, Caput Quoniam (1299) 1,7,1 in VI; "Const. Apost. Vasantis Anostolicae Sedis", n. 8: AAS 38 (1946) 65-99; Paulo VI, "Motu proprio Apostolica sollicitudo, 15 sept. 1965": AAS 57 (1965) 775. 
yen el Colegio Episcopal, una de las aportaciones más valiosas del Concilio Vaticano II al tema de la participación de los obispos en el régimen de la Iglesia universal. Pueden actuar conjunta o individualmente en cuanto a la parte del Señor que se les ha confiado, teniendo cada uno el cuidado de la Iglesia, que preside, o en ocasiones proveyendo algunos de ellos conjuntamente ciertas necesidades comunes a diversas Iglesias; por eso dentro de la sección de los obispos hay una subdivisión: $1^{a}$ El Colegio Episcopal (cc. 39-46). $2^{a}$ De cada uno de los obispos (cc. 47-48): "Cada uno de los obispos a los que ha sido confiado el cuidado de alguna Iglesia particular, la presiden como vicarios y legados de Cristo, y bajo la autoridad de la suprema potestad, apacientan la porción del pueblo de Dios a ellos confiada, como propios ordinarios e inmediatos pastores suyos, al ejercer sobre ella las funciones de enseñar, santificar o gobernar, salvando siempre los derechos que legítimamente competen a los $\mathrm{Pa}$ triarcas y a otras autoridades jeráquicas" (c. 47) ${ }^{25}$.

Parágrafo $3^{\circ}$ De los presbiteros y diáconos (cc. 49-50).

Los presbíteros, aunque no poseen la plenitud o culmen del Pontificado, parícipan con los obispos del único y verdadero sacerdocio de Cristo, "son colaboradores y forman con el obispo el único presbiterio según los modos determinados por el Derecho en el gobierno del pueblo" (c. 49). "Para el ejercicio de la función encomendada tanto a los obispos como a los presbíteros, son colaboradores los diáconos, quienes fortalecidos con la gracia sacramental del Orden, son destinados a que, en comunión con el obispo y su presbiterio, sirvan al pueblo de Dios en el ministerio de la liturgia, de la palabra y de la caridad, según les sea asignado por la autoridad competente" (c. 50) ${ }^{26}$. Se han procurado conciliar los principios de colegialidad y descentralización con la participación sin pretender inclinar la balanza a ninguno de los dos lados. Los obispos tienen la plenitud del Orden sacerdotal, mientras que los presbíteros y diáconos participan por comisión, delegación, concesión.

25. Cf. Const. dogm. Lumen gentium nn. 3,22,23 y 27; Decr. Christus Dominus nn. 11 y 27; Decr. Ecclesiarum Orientalium n. 23.

26. Cf. Const. dogm. Lumen gentium nn. 23, 28-29; Decr. Presbyterorum Ordinis nn. 2,7,12,16-22; Decr. Apost. actuositatem nn. 2 y 10; Const. Sacrosanctum Concilium n. 6. 
Queda aún pendiente de una mayor precisión en la doctrina, hasta qué punto se pueden comisionar a los laicos algunas funciones eclesiásticas sin participar en el sacramento del Orden, que de suyo lleva ya anexos algunos derechos y deberes especiales. En esta como en otras materias, es digna de alabar la prudencia y delicadeza de la Comisión para la Reforma del Código, al no pronunciarse canónicamente en temas cuya decisión excede los límites de su competencia.

\section{b) CAP. II: DE LAS FUNCIONES DE LA IGLESIA}

El capítulo segundo del esquema, en vez de seguir el orden romanístico de Gayo, desarrolla los tres munera de Cristo: enseñar, santificar y regir. Se sigue la orientación propuesta por la Teología moderna formulada en el Concilio Vaticano II. A cada una de las funciones le corresponde un artículo específico.

En los cánones preliminares (cc. 51-53) se desarrolla la institucionalización y transmisión de estas funciones tal como aparecen en el Nuevo Testamento. El centro está constituido por el misterio eucarístico, que viene a ser como el culmen a que tiende la acción de la Iglesia (c. 52). Estas funciones son encomendadas específicamente a los obispos, presbíteros y diáconos. "Los fieles, por haberse incorporado a Cristo mediante el bautismo y participar en su modo propio del oficio sacerdotal, profético y real de Cristo, ejercen por su parte la misión de todo el pueblo cristiano en la Iglesia y en el mundo" (c. 53) ${ }^{27}$.

Articulo 1.: De la función de enseñar propia de la lglesia (cc. 54-62).

Tanto la función de enseñar, como las demás funciones, son ejercidas por los titulares de oficios o por los que han sido autorizados para suplirles jurídicamente. Cristo confió a su Iglesia el depósito de la fe con el derecho y deber de predicar el Evangelio a todas las gentes (c. 54). El pueblo de Dios participa también del oficio profético y tiene el sentido de la fe, que alienta y sustenta el Espíritu Santo (c. 55). La infalibilidad del magisterio es competen-

27. Cf. J. A. SouTo, "De Ecclesiae muneribus": El Proy. de LEF... 180190; Const. Sacrosanctum Concilium nn. 7,9-10; Decr. Ad gentes n. 39; Const. dogm. Lumen gentium nn. 2,10,21 y 28; St. Tomas, Summa Theol. III, q. 65 , A. 1 , q. 79 , a. 1 , c. et ad 1. 
cia por una parte del Romano Pontífice y por otra parte del Colegio Episcopal (c. 56). Hay obligación de creer con fe divina y católica la palabra de Dios escrita o de tradición y lo que se propone por el Magisterio de la Iglesia, solemne u ordinario y universal, como divinamente revelado (c. 57). Se ha de prestar un asentimiento y aceptación obsequiosa a la doctrina de fe y costumbres propuestas por el magisterio eclesiástico (cc. 58-59). Hay obligación de difundir el Evangelio por parte del Colegio Episcopal, del Romano Pontífice, de los obispos diocesanos, de los presbíteros, de los diáconos y de los religiosos (cc. 60-61). "Todos los fieles tienen obligación de difundir el Evangelio, no obstante, para que alguno pueda ejercer el ministerio de la palabra de Dios en nombre de la Iglesia, debe recibir una misión de la autoridad competente, bien mediante facultad especialmente concedida, o bien por la colación de un oficio que lleva consigo esta función, según los sagrados canones" (c. 62). ${ }^{28}$.

Artículo 2.: De la función de santificar propia de la lglesia (cc. 63-74).

Estos cánones vienen a ser como un compendio teológico catequético porque tratan de hacer de la LEF una ley precisamente pastoral. Se establece la misión santificadora que "se ejerce principalmente por la oración, las sagradas celebraciones litúrgicas, el sacrificio eucarístico y los demás sacramentos" (c. 63). Después de señalar que los sacramentos han sido instituidos por Cristo y que compete a la Iglesia su regulación para la válida y lícita administración (c. 64), se ratifica en el proyecto que la función de santificar corresponde en primer lugar a los obispos, luego a los sacerdotes presbíteros, como ministros suyos, y también a los diáconos (c. 65). Luego se especifica en los siguientes cánones (cc. 66-72) a quiénes corresponde administrar los sacramentos, efectos jurídicos etc. En el c. 73 se deiermina que la Iglesia lleva a cabo la función de santificar por medios diversos principalmente por la oración de los fieles: "Para fomentar la santificación del pueblo de Dios, la Iglesia promueve el verdadero culto a los santos... y honra con filial y particular veneración a la B. V. María, la cual al

28. S. Agustin, De Praed. Sanct. 14,27 PL 44,980; Conc. Vat. I, Const. Dogm. Pastor aeternus c. 4; DENz. 1839; Const. dogm. Dei Filius c. 3: Deñz. 1712 y 1792 ; Conc. Vat. II, Const. dogm. Lumen gentiı!m nn. 23,25 y 29. PAUlo VI, "Homilia en la novena sesión del Concilio Vaticano II, 7 de diciembre de 1965": AAS 58 (1966) 51-59. 
acoger la palabra divina fue hecha madre de Dios Salvador, dispuesta a servirlo en el misterio de la redención, y a la que Cristo constituyó madre de todos los hombres" (c. 74) ${ }^{29}$.

Artículo 3.: De la función de regir propia de la Iglesia (cc. 75-83).

Dentro del poder de regir o del gobierno espiritual se distinguen tres potestades: legislativa, ejecutiva y judicial. "Quienes detentan esta potestad la utilizan sólo para edificar el pueblo de Dios en verdad y santidad" (c. 75). A continuación se especifican ampliamente el ejercicio primacial y colegial de los obispos. Se describen los órganos y oficios encargados de ejercer la potestad de regir a la Iglesia, quedando todavía un poco acentuado el poder centralizador. Se expresa el origen de la potestad y se menciona a! Romano Pontífice y al Colegio Episcopal, que "tienen plena y suprema potestad para regir al pueblo de Dios por institución divina" (c. 76). Luego, en los cc. 77,78 y 79 se procura clarificar un poco la confusa división tripartita de potestades: legislativas, ejecutivas y judiciales, que están un poco entremezcladas en la Iglesia, aunque se prevee la posibilidad de establecer órganos distintos, por ejemplo, legislativos de ámbito universal como colaboradores del Papa, lo mismo que ya existen en lo judicial.

En los cc. 80 y 81 se dan los delineamientos sobre la posición del obispo diocesano, cabeza de la Iglesia particular. Su autonomía está limitada con relación al poder del Romano Pontífice. Aparecen también estructuras, jerarquías intermedias: Sínodos Patriarcales, Concilios particulares, Conferencias Episcopales, Patriarcas, Metropolitas etc. El último canon, como en los demás artículos, trata de los fieles laicos, "que pueden ser llamados a prestar personal ayuda al obispo en el gobierno del pueblo" (c. 83). "Obligan las costumbres universales introducidas por el pueblo cristiano y aprobadas por la autoridad eclesiástica" (c. 77 \$2). Se reconoce al pueblo la capacidad de introducir y crear costumbres con ciertas limitaciones ${ }^{30}$.

29. Cf. Const. dogm. Lumen gentium nn. $10,11,26,28,29,40,41,50 ; 53 ; 54$ 61-66; Conc. Flor. Decr. pro Armenis, de sacramentis: Denz. 696,699,700, 1324 etc. Conc. Trid. Sess. 23, c. 6, n. 11; Sess. 7, de sacramentis in genere c. 1; Sess. 24, de matrimonio, proemium c. 1.

30. Cf. PIo IX, Litt. Encl. Quanta cura 8, dic. 1864; DENz. 1968; LEON XIII, Ep. Enc. Inmortale Dei, 1 nov. 1885, nn. 5-6; BenEDICTo XV, "Motu 
c) CAP. III: DE LA IGLESIA Y LA SOCIEDAD HUMANA (cc. 84-95)

En este capítulo tercero se dan las directrices de las relaciones entre la Iglesia y las demás sociedades dentro de la comunidad internacional. Estas relaciones quedan planteadas en una triple dimensión: política, religiosa e internacional ${ }^{31}$.

En el c. 84 se hace referencia a los principios estimativos y pragmáticos de los pastores sobre los nexos entre la Iglesia y la comunidad política (Estado). La Iglesia reconoce que su misión es esencialmente religiosa y no política. Por esta razón se distingue y separa de las demás sociedades. Reconoce igualmente la autonomía propia de las sociedades de orden temporal; no se habla de la potestad directa o indirecta de la Iglesia; pero ésta sigue reivindicando el derecho y deber de dar luces y orientaciones, recomendando a los fieles laicos, conforme a su propia vocación, a que trabajen para que "las realidades terrenas y también las sociedades temporales se ordenen a Dios" (c. 85 \$2).

Dejando a salvo la autonomía e independencia, tanto la Iglesia como la sociedad política, "cumplen más eficazmente la función propia para el bien de sus miembros, si practican una sana cooperación, en cuanto la aconsejen y permitan las circunstancias de lugar y tiempo" (c. 86). La Iglesia se sitúa en un plano de conciliación más que de enfrentamiento al Estado, con quien procura establecer relaciones para salvar su independencia y libertad. En última instancia, la Iglesia, en caso de no poder llegar a un posible acuerdo, tendría que estar dispuesta a vivir en estado de persecución para que, a cambio de una libertad formal, no se le prive de su li-

Proprio Cum Juris Canonici Codicem, 15 sept. 1917": AAS 9 (1918) 483; Pro XI, "Litt. Enc. Divini Illius Magistri, 31 dic. 1929": $A A S 23$ (1930) 53; PIo XII, Motu Proprio Sollicitudinem Nostram 6 enero (1950) cc. 1-16; Conc. Vat. II, Decr. Christus Dominus nn. 8,11,25-26; Decr. Apost. actuositatem nn. 10, 24-26; Const. dogm. Lumen gentium nn. 20,22,23,28,29,32, 37 y 42 .

31. Paulo VI, "Allocutio secunda Sess. Concili Vaticani II, periodo ineunte, habita 29 sept. 1963": $A A S$ 55 (1963) 841-859; cf. "Trattato fra la Santa Sede e l'Italia, 11 febr. 1929, a. 2-24: AAS 21 (1929) 210-229; Conc. Vat. II, Const. dogm. Lumen gentium nn. 36-38; Const. Past. Gaudium et spes nn. 36,40,76 y 89; Decl. Dionitatis humanae nn. 4,12,13-15; J. Calvo, "Notas críticas al cap. III del esquema de la LEF": El Proy. de LEF... 200206 ; A. Perlado, "La Iglesia y la Comunidad Internacional": El proy. de L... 207-213. 
bertad substancial necesaria para defender sus principios, dogmas y misión pastoral.

La Iglesia se presenta, por su universalidad e independencia "como vínculo entre las diferentes comunidades humanas y las naciones" (c. 87). Quiere integrarse por esta vía al concierto internacional de las naciones y comunidades religiosas, "al mismo tiempo que estima en mucho la contribución y realizaciones de las otras Iglesias o comunidades eclesiásticas al bien de la humanidad" (c. 88 \$2), vindicando para sí y para las demás comunidades religiosas los mismos derechos en el uso de su libertad religiosa. En los cánones 89 y 90 se amplía el derecho a la libertad plena y perfecta de cualquier sociedad humana en su misión de salvar a los hombres, reproduciendo la doctrina del Concilio Vaticano II en esta materia: "Es de justicia que pueda la Iglesia en todo momento y en todas partes predicar la fe con auténtica libertad, enseñar su doctrina sobre la sociedad, ejercer su misión entre los hombres sin traba alguna y dar juicio moral, incluso en materias referentes al orden político, cuando lo exijan los derechos fundamentales de la persona y la salvación de las almas" 32.

Sigue insistiendo el esquema aún con vigor en los derechos de la Iglesia a procurar la educación religiosa y moral, a fundar escuelas etc. (c. 91) y a utilizar los medios de comunicación social (c. 92) especialmente para comunicarse libremente con los obispos (cc. 93-94). Se reclama también libertad para establecer seminarios, instituciones de caridad etc. Conciuye el canon 94 refiriéndose a la necesidad de los bienes materiales: "Para dedicarse al bien espiritual de los hombres, la Iglesia necesita bienes temporales y los utiliza en la medida en que su misión propia lo reclama. Por tanto, corresponde a la Iglesia el derecho innato a adquirir, retener y administrar los bienes temporales que requieren sus propios fines, sobre todo, para ordenar el culto divino, para la honesta sustentación de sus ministros y también para ejercer el apostolado y la caridad" (-c. $94 \$ 4$ ). El último canon del capítulo tercero y de la LEF contiene una declaración interesante, en la que la Iglesia se define no como sociedad perfecta, sino como personalidad internacional: "La Iglesia, en cuanto posee personalidad en la sociedad universal de gentes, une sus fuerzas con las sociedades civi-

32. Const. past. Gaudium et spes n. 76. 
les en un mismo empeño de fomentar la justicia, la cooperación, la concordia y la paz entre todas las gentes" (c. 95 \$1).

"\$2. Sin embargo, la Iglesia participa de los esfuerzos y actividades de esta sociedad de gentes solamente en las causas que pertenecen a su misión espiritual, principalmente para alentar la paz en el mundo conforme al espiritu del Evangelio. Roma 25 de julio de 1970" ${ }^{33}$.

Aunque el Textus prior como el Textus emendatus publicados en revistas tienen distintas fechas, según el momento y la persona que sirvió de vehículo, en el fondo coinciden doctrinal y literalmente con los ejemplares enviados a los obispos y consultores. A falta de un texto oficial, que no se publicará hasta que la Comisión lo considere oportuno, pueden utilizarse los ejemplares divulgados del Textus emendatus. Para ver una síntesis en conjunto, se presenta a continuación un resumen esquemático del proyecto de la LEF del Textus emendatus, que no coincide con el textus prior en la numeración de los cánones a partir del c. 25 (añadido).

Proemio o introducción: principios teológicos fundamentales.

c. 1: Naturaleza, fin y estructura de la Iglesia, como pueblo de Dios.

c. 2: Unidad y multiplicidad de la Iglesia.

Artic. 1.: De todos los fieles en ge-

Cap. I: De la lglesia, pueblo de Dios

(cc. 1-50)

trata de

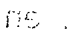

$-800$

Ésquema

de $/ \mathbf{a}$

$E F$

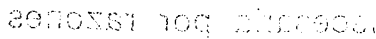
neral.

cc. 3-25: Derechos y obligaciones de los fie'es.

cc. 26-30: Diversidad por razón de de estado.

Artíc. 2: De la jerarquía ecles. (cc. 31-33).

\$1: Del Sumo Pontifice (cc. 34-36). $\$ 2$ : De los obispos en general (cc. 37-38).

1 Colegio do los obisp. (cc. 39-46).

2 De cada uno de los obispos (cc. 47-48).

33. J. Hervada y P. Lombardia, El derecho del Pueblo de Dios (Pamploña 197.0) 256-265; A. Rouco VARELA y E. CoRecco, Sacramento e Diritto: antinomia nella chiesa? (Milán 1971) 30-76; J. RATZINGER, La Unidad de 
\$3: De los presb. y diáconos (cc. 49-50).

Cap. II: De las fun- Funciones ecles. en general (cc. ciones de la Igle- 51-53).

sia.

(cc. 51-83).

Artíc. 1: Función de enseñar (cc. 54-62).

Artíc. 2: Función de santificar (cc. 63-74).

Artíc. 3: Función de regir (cc. 7583).

Cap. III: De la Iglesia y la sociedad

No tiene divisiones en artículos, pero puede subdividirse en cuatro puntos:

humana.

1. Iglesia y sociedad política (cc.

(cc. 84-95).

84-87).

2. Iglesia y comun. relig. (c. 88). 3. Libertad plena y perfecta (cc. 89-94).

4. Iglesia y socied. intern. (c. 95).

\section{EL PROYECTO ANTE LA CRITICA}

Conviene tener en cuenta la opinión formulada por el Papa Paulo VI el 20 de enero de 1970 en una alocución a los asistentes al Congreso de Derecho Canónico celebrado en Roma. Refiriéndose expresamente a la LEF, llamó la atención con algunas observaciones y reflexiones sobre la necesidad de buscar el por qué y el cómo del nuevo ordenamiento jurídico-canónico en la constitución mistica de la propia Iglesia. Esto supone ahora una renovación en el estudio y en la formulación de la LEF y de todo el Derecho Canónico, que debe ser deducido de la misma esencia mística de la Iglesia. Los canonistas estaban acostumbrados a basar su doctrina sobre la tradición secular fundamentada principalmente en el Derecho Romano y en los Derechos de otros pueblos convertidos al Cristianismo. La actual revisión no sólo es necesaria por razones

las Naciones. Aportaciones para una Teología Política (Madrid 1972) 6880. 
prácticas, que motivaron la redación de todas las compilaciones canónicas del pasado, sino sobre todo, porque así lo exige una comprensión más profunda de la misma Iglesia. Hoy se critican los principios tradicionales y es necesario volver principalmente a la Ley evangélica del amor y de la gracia del Espíritu Santo, que es el principio interno de la acción en la Iglesia, para expresarse cada vez mejor en su orden externo y social ${ }^{34}$.

El Papa dio los delineamientos, cuyas consecuencias y características se irán viendo en la fisonomía de la LEF y en la revisión del Código de Derecho Canónico. La mezcla de elementos teológicos y juridicos ha ocasionado no pocas complicaciones, que se han ido solucionando, conciliando lo carismático con lo jurídico para proporcionar una genuina noción de la Iglesia: así al leer la LEF, todos podrán saber en qué consiste y qué es la Iglesia de Cristo.

\section{a) Caracteristicas del proyecto de LEF}

La redacción del esquema de la LEF, producto de muchas reflexiones y colaboraciones, a pesar de la variedad de textos y principios recogidos, ofrece uniformidad de estilo, con un lenguaje canónico, técnico y bastante preciso. La profundidad de contenido obliga a mantener textos de indole doctrinal y expresiones conciliares de densa significación. La actual LEF no se puede comparar con el Código de 1917, no es que sea mejor o peor, sino que es algo muy distinto.

Por tratarse de una Ley fundamental, stricto sensu constitutionalis, ocupará un rango supremo en el ordenamiento eclesiástico, algo asi como la cúspide de la pirámide jurídica del pueblo de Dios: por tanto, cualquier ley contraria habrá que declararla nula. En el fondo de la cuestión subyace un problema muy delicado por su penetración en el misterio de la Iglesia difícilmente subsumible bajo la tipicidad de las leyes. El ejercicio de la autoridad del Papa, como Primado de Roma y Vicario de Cristo, no podría someterse a un condicionamiento constitucional en lo tocante a la infalibilidad por tratarse de un dogma definido en el Concilio Vaticano I; pero podría someterse en cuanto a lo administrativo, según se hizo notar

34 AAS 62(1970)106- 111. 
anteriormente. Teólogos y juristas conjuntamente deben buscar solución a esta problemática. Algunos, como K. Mörsdorf y T. García Barberena, opinan que el poder del Papa podría estar constitucionalmente determinado, y de hecho ya lo está poŕ los mismos Evangelios; pero no pueden someterse sus actos a revisión, como los de un Presidente constitucional, ni cuestionar su infalibilidad ${ }^{35}$.

En la LEF pueden distinguirse dos elementos claramente precisables: uno teológico-revelado y otro humano-jurídico. La organización de la Iglesia particular, bajo la dirección de su obispo, deberá adecuarse a los principios constitucionales, que rijan la Iglesia universal.

Toda legislación particular debe ser congruente con la LEF, expresando al mismo tiempo las caracteristicas peculiares y genuinas de cada comunidad según la tradición litúrgica, jurídica y cultural. En esto pueden y deben desempeñar un papel muy importante los Episcopados nacionales y regionales. De ahí que el contenido definitivo de la LEF esté lógicamente condicionado a las respuestas, que han enviado los obispos ${ }^{36}$. No tenerlas en cuenta sería elaborar un texto cadavérico, de espaldas a la realidad y sin posibilidades de vigencia en el futuro. La mayoria de los obispos y canonistas consultados están de acuerdo en reconocer que se trata de una Constitución formal de la Iglesia; que su cuerpo es de naturaleza legal con un lenguaje jurídico; que no es necesaria la pretensión de repetir los principios teológicos enunciados en el Concilio Vaticano II. Sin embargo, algunos opinan lo contrario y estiman que debían estar en la introducción los principios básicos. Entre las 184 citas, algunas de contenido múltiple, que figuran al pie del Textus emonciatus, se acumulan notas conciliares y del Magisterio, sin que falten citas bíblicas en el mismo texto. Después de la promulgación de la LEF serán necesarios estudios críticos para conocer sus fuentes. No estaría mal se editasen aparte con la historia del proyecto, según se ha hecho con el Código del año 1917.

35. Coloquio Hispano-Germano 21 de enero de 1972, diálogo entre T. GARCIA BARBERENA y K. MORSDORF sobre la Const. dogm. Pastor aeternus Denz. 1821-1829; Conc. Vat. II, Const. dogm. Lumen gentium 18; Cf. "Valor LEF": Communicationes 3 (1971) 62.

36. Communicationes 4 (1972) 122-160; Cf. "De materla LEF": Communicationes 3 (1971) 63-66; G. THILS, "Communicationes et la LFF": Revue théologique de Louvain 1 (1970) 228-230. 
Las leyes requieren una formulación técnica y legal, tal como se está haciendo con la LEF. "A las leyes, no hay que pedirles que tengan estilo evangélico, sino que ordenen la vida social de tal manera que las actitudes genuinamente evangélicas encuentren amplio cauce en el terreno de la praxis" ${ }^{37}$.

La LEF, necesaria para una reorganización de la Iglesia, resulta viable y conveniente, no sólo porque recoge en ella pasajes biblicos y textos conciliares, dándoles un tono más o menos jurídico, sino porque con el consentimiento de la mayoría de los obispos y de los especialistas consultados en representación de la opinión pública, puede aportar muchas y grandes ventajas para una estructuración de la Iglesia más evangélica, contemporánea y abierta ampliamente al soplo del Espíritu Santo y a las nuevas posibilidades democráticas.

Bastantes obispos americanos, con mentalidad constitucionalista y democrática, han insistido en la necesidad de una Constitución un poco semejante a la de los Estados liberales y común a todas las Iglesias católicas conforme al esplritu del Evangelio, de la tradición y de las necesidades actuales del pueblo de Dios. La declaración de los derechos de los fieles es algo común a todas las Constituciones democráticas. La LEF procura establecer garantías en los cc. 3-30 para tutelar la seguridad humana y su libertad conforme a los postulados del Derecho divino, natural y de la cultura de occidente. La LEF no puede dar gusto a todos, porque esto es imposible; ni puede adelantarse a la doctrina común, ni a la investigación, por lo que se evitan, en la Comisión de estilo, expresiones "que impliquen una toma de posición en cuestiones que en el momento actual se discuten legítimamente por la doctrina, tanto en el terreno teológico como en el canónico" ${ }^{38}$.

El proyecto de Constitución formal de la Iglesia procura conciliar lo evangélico con lo jurídico trazando las líneas maestras del ordenamiento eclesiástico. El mismo nombre de LEF no es una novedad en el campo constitucional, ya que, por ejemplo, la Constitución de la República Federal Alemana se denomina Ley Funda-

37. P. Lombardia, "Entrevista, Panorámica del Proyecto": El Proy. de Lef. 85; Cf. J. NEUManN y J. Ratzinger, Theologie im Wandel (München 1967) 415-448; W. KASPER, Kein Grundgesetz der Kirche ohne Zustimmung der Christen (Mainz 1971) 18-30.

38. J.L. GuTIERREz, "Situación presente y perspectivas futuras de la LEF": Ephemerides Juris Canonici 27 (1971) 289. 
mental: Grundgesetz en vigencia desde mayo de 1949. Hay bastantes influencias germánicas en la LEF.

Según la opinión mayoritaria, la promulgación debe revestir cierta solemnidad, propia de una Constitución, aunque se ha evitado este nombre por su doble sentido institucional y normativo, y por razón de orden práctico; pues se está aún en un período de gestación y perfeccionamiento. El Sínodo Episcopal con el Romano Pontífice o un Concilio Universal serían órganos legislativos competentes para promulgar la LEF como principium et fundamentum unitatis Ecclesiae. Podria ser hecha la promulgación por el Papa actuando colegialmente con los obispos, a quienes se ha consultado y están prestando el debido asesoramiento, teniendo en cuenta las aportaciones de teólogos y canonistas.

Aunque no está bien delimitado el papel que corresponde a la comunidad de los cristianos en el desarrollo del proyecto de la LEF, ni en la elaboración de las leyes, se da mayor participación a los laicos cristianos, especialmente a los más capacitados o expertos, que pueden ser consultados a la hora de hacer las leyes y en algunos casos debería hacerse para conocer la opinión pública ${ }^{39}$.

b) Observaciones generales y especiales, que se han hecho al proyecto:

La mayoría de las críticas y observaciones publicadas en revistas han sido recogidas por los obispos y remitidas a la Comisión especial de Roma, según puede comprobarse en la Relatio universas contrahens generales animadversiones ad Schema LEF ab Episcopis propositas, presentada al Sínodo de Obispos el 3 de noviembre de 1971. Estas críticas y observaciones han sido examinadas $y$ consideradas por los miembros del Coetus specialis en la sexta sesión (20-24 de noviembre de 1972) ${ }^{40}$.

Algunas de las observaciones generales coinciden con las características del proyecto de la LEF, que vimos anteriormente al tratar de la naturaleza, fin y valor de la LEF como algo constitucio-

39. A. DEL PORTILlo, Fieles y laicos en la Iglesia. Bases de sus respectivos estatutos jurídicos (Pamplona 1969) 160-167; Cf. Ch. Lefebre, "Vers une tecnique législative nouvelle: la LEF": L'Année cononique 15 (1971) 593-595.

40. Communicationes 4 (1972) 120-160; 5 (1973) 196-216. 
nal. Ahora se recogen solamente algunas referentes a la materialidad de la LEF y su especificación, haciendo un resumen de las más pertinentes, oportunas y criticables. La mayoría de los obispos orientales insisten en que se dé acogida en la LEF a estructuras orientales porque la LEF seu constitutio quaedam nimis sapit ideas occidentales. Ruegan que se tenga más en cuenta la tradición oriental y se haga equilibrio a la concepción jurídica latina... per conceptionem magis pneumaticam Orientalium ${ }^{41}$.

Hay observaciones que se refieren al método, estilo y redacción definitiva por una persona competente o un grupo reducido, no muchos, porque complicarían la tarea después de haber pasado el esquema por los consultores, obispos, peritos, hombres y mujeres etc. en representación de toda la Iglesia latina y oriental ${ }^{42}$.

Algunos opinan que en el esquema hay mucho sobre la jerarquía, Papa y obispos, miemtras es poco lo que dice de los presbí: teros, diáconos, religiosos y laicos; que es necesario una reorganización del poder y su ejercicio en la Iglesia, dando más relevancia a las nuevas instituciones: Sínodo Episcopal, Consejo Presbiterial, Consejo de Pastoral etc. Unos proponen que se hable más de los carismas del pueblo; otros que no está bien definida la participación de los laicos en la Iglesia ${ }^{43}$.

La reflexión sobre el fenómeno religioso y el proyecto LEF ha llevado a no pocos a hacer consideraciones diversas sobre el concepto de pueblo de Dios y la vinculación con los hermanos separados, a los que hace referencia como tratando de tender un puente de acercamiento. Alguno que otro opina que con la LEF aumentará la separación. Algún canonista defiende que antes de dar normas sobre los hermanos separados, habría que dilucidar la cuestión de fondo, "de si pertenecen y en virtud de qué título los hermanos separados al orden jurídico de la Iglesia Católica" "4.

41. Communicationes 4 (1972); 138-139.

42. Ibid., $159-160$.

43. Ibid., 145-148.

44. J. ARIAS, "Los cristianos separados": El Proy. de LEF... 111-117. Para ver la situación de los evangélicos y protestantes G.R. Dunstan, "A Curial Constitution": Communicationes 4 (1972) 212-213; P. MaLlia, "Organización de la Iglesia inglesa": Augustinianum 4 (1964) 54-76 у 489-536; W. Stenmuller, "La Teología del Derecho entre los protestantes y el Derecho Canónico de los católicos": Concilium 48 (1969) 187-201; J. M. Rouco VARELA, "Teología protestante contemporánea": Revista Española de Derecho Canónico 26 (1970) 117-143. 
Para seguir un orden sistemático en las críticas formuladas principalmente por los obispos, se resume a continuación lo publicado en Comunicaciones sobre las estructuras internas y la división de la LEF.

$1^{\circ}$ En cuanto al proemio: Es deseo de la mayoría de los obispos que permanezca el proemio o introducción. Algunos desean ampliar y otros disminuir. La ampliación sería con los fundamentos teológicos y jurídicos, elementos de Derecho divino y eclesiástico más importantes etc. Que se explique la fundamentación de las leyes, su naturaleza, su obligatoriedad etc. No faltan quienes proponen se hable en la introducción sobre la Iglesia de la caridad, pneumática, vital, existencial y no jurídica. Por el contrario, otros defienden que se margine todo lo teológico para quedarse con lo jurídico propio de la LEF. En el proemio - añaden algunos- deberían explicarse los conceptos de equidad, epiqueya, oikonomía oriental etc. La principal observación en cuanto al proemio es la de aquellos que exigen una introducción mayor, donde se expongan los principios fundamentales teológicos y jurídicos, naturaleza de la Iglesia etc. según los documentos conciliares ${ }^{46}$.

$2^{\circ}$ En cuanto a la división: La mayoria está de acuerdo con los tres capítulos, aunque hace bastantes observaciones al orden sistemático: Una Conferencia Episcopal propone la división en cinco capítulos así: Cap. I: De la Iglesia, como comunidad y sociedad en en sus aspectos fundamentales etc. Cap. II: De las personas, de los oficios y derechos fundamentales de los miembros del pueblo de Dios por razón del bautismo. Cap. III: De los ministerios. Cap. IV: De la extensión de la Iglesia en su constitución y su formación (diimensión misionera). Cap. V: De la presencia de la Iglesia en el murćs. Otra Conferencia propone tres capítulos con este orden: 1 : Del pueblo de Dios. II De la misión de la Iglesia en el mundo. III. De las funciones de la Iglesia. Algún obispo propone la división en cuatro capítulos siguiendo el orden del proyecto y haciendo del artículo 2. del Cap. I. un capítulo aparte con este título: De la jerarquía de la Iglesia. Dan argumentos para justificar sus asertos ${ }^{47}$.

3. En cuanio al capítulo primero: Hay observaciones genera-

45. Communicationes 4 (1972) 152-160.

46. Ibid., 152-153.

47. Ibid., 153-154. 
les y concretas sobre la declaración de los derechos y deberes de los fieles. Algunos la consideran como una repercusión de la declaración formal hecha en París el 10 de diciembre de 1948, aunque hay formulaciones anteriores implícitamente en los Evangelios, más explícitamente en la Carta Magna Inglesa (15 de junio de $1215)$, en algunos juristas hispano-americanos del siglo XVI, en las Leyes de Indias, en la Enciclopedia Francesa etc. Se crítica esta materia, según se hizo notar anteriormente, porque no basta con hacer declaraciones, sino que es necesario asegurar esos derechos: se reconocen deficiencias en la LEF al no proteger los derechos 0 al menos algunos fundamentales con las garantías procesales ${ }^{48}$.

Algunos proponen no se hable de "pueblo de Dios" sino de Igiesia. Otros, refiriéndose al art. 2 dicen que debe desaparecer la jerarquía. La mayoría está de acuedo en que permanezca lo que hay sobre la jerarquía con nuevas divisiones y subdivisiones para asegurar la colegialidad y descentralización. Se reconoce que todo el capítulo primero está bien redactado en general con una labor muy positiva y bastante perfecta. Falta, sin embargo, una clara disposición relativa a la jerarquía de las normas y control judicial en la actividad administrativa. Hay que dar más participación a las mujeres en los tribunales eclesiásticos, notarías y gestiones administrativa. A los presbíteros no basta con llamarles colaboradores, deberian ser mencionados como responsables, especialmente los párrocos y los sacerdotes con cura de almas. Sobre los religiosos -insisten algunos - debe aclararse mejor el texto de los vínculos, que constituyen el estado religioso, votos etc. Que se aclare más lo referente a los diáconos y laicos. Ya en la LEF se hace referencia a que se actuará conforme a las normas de los sagrados cánones, ad nornam sacrorum canonum en determinadas circunstancias, dando a entender que no se puede resolver todo en un instrumento constitucional ${ }^{49}$.

4. Sobre el capítulo segundo, funciones de la Iglesia, hay algunas observaciones generales. Los órganos competentes encargados de dar las leyes y aplicarlas no deben ser los mismos. Convie-

48. P. Lombardia J., Souto, J. Hervada, "Sugerencias para la revisión del proyecto de LEF": El Proy. de LEF... 219; Cf. P. DE LA CHAPELIE, La déclaration universelle des Droits de l'Homme et le Catholicisme (Paris 1967); J.M. SErien, "Persona humana e tutela dei diritti nell'ordinamento canonico": La Collegialità episcopale per il futuro della chiesa (F1renze 1969) 81-127.

49. Communicationes 4 (1972) 155. 
ne delimitar mejor los límites de la competencia con una nítida separación de poderes.

La mayoría está de acuerdo con el orden y desarrollo de los munera. Una Conferencia Episcopal problematiza la división tripartita, como no completa, porque obscurece un poco las funciones sanctificandi et docendi. A otra Conferencia no le satisface la división alegando repeticiones inútiles. Dos obispos utilizan casi las mismas palabras procurando demostrar que estas funciones son propias de la jerarquía: munus docendi, sanctificandi ac regendi pertinent solummodo ad episcopos, et ad cooperatores Ordinis episcopalis, presbyteros; omnes christifideles, vi baptismatis recepti, participant Christi munus propheticum, sacerdotale et regale ${ }^{50}$.

Otra observación propone se corrija lo referente a las funciones de los presbíteros actuantes en nombre de Cristo y no de los obispos. Que se aclare lo de los oficios en su concepción orgánica-sacramental. Incluso se aconseja el aditamento de un nuevo canon, donde aparezca el oficio que todos tienen de adorar al creador. ${ }^{51}$.

5. En cuanto al capitulo tercero: Iglesia y sociedad humana, es donde hay mayor número de observaciones muy diversas y hasta contrarias. Es el tema más candente por sus antecedentes y consecuencias. Para comprender un pcco los antecedentes de esta encrucijada, basta con tener en cuenta la actuación del Papa Paulo VI, quien cuando era aún Cardenal Montini pronunció un discurso la víspera de la apertura del Concilio Vaticano II en el Ayuntamiento de Roma anunciando en su disertación que el Concilio sería el fin de la época contantiniana (maridaje Iglesia y Estado) y el fin de la contrarreforma" (versión activa de ese mismo postulado). En el Concilio Vaticano II, concretamente en la Constitución Gaudium et spes se dieron principios orientadores, diciendo que "la comunidad política y la Iglesia son independientes y autónomas, cada una en su propio terreno". Esto es fácil decirlo; pero hacerlo realidad es tan angustioso como pasar de Montini a Paulo VI, de una conferencia a una encíciica, según comentaba con su gracia andaluza D. José María Pemán, nada sospechoso de parcialidad en esta materia ${ }^{52}$.

50. Ibid., 155-156.

51. Ibid., 157.

52. J.M. Peman, "La visita al Papa": $A B C 18$ sept. (1973) 3. 
Las consecuencias de las relaciones entre la Iglesia y el Estado las estamos viendo en España, uno de los pocos países confesionalmente católicos, donde se puso en práctica por primera vez no el constantinismo bizantino sino el agustinismo político: unión y colaboración de la Iglesia y el Estado. Hace poco más de un año, cuando se estaba gestando en la Conferencia Episcopal Española el documento La Iglesia y la Comunidad política, surgió una escisión en la fraterna caridad del episcopado con proporciones tan alarmantes que no solamente se hizo eco la prensa, sino que hasta el mismo Nuncio del Papa se presentó en la XVI Asamblea Plenaria del Episcopado, el 10 de marzo de 1972, no con una carta de felicitación de Roma, sino con cinco folios bien densos y documentados exponiendo las directrices de la Iglesia en esta materia: $1 .^{a}$ Libertad e independencia de la Iglesia para su pleno desarrollo y ejercicio de sus funciones espirituales. 2." La Iglesia tiene el derecho y el deber de ocuparse de realidades temporaies para cumplir su misión. 3. ${ }^{a}$ Deber de obediencia a las autoridades con mutua colaboración. 4. ${ }^{a}$ No interferencia de la Iglesia en la competencia del Estado etc. Para probar estos cuatro principios se citan no sólo documentos conciliares sino también las encíclicas desde León XIII hasta Paulo VI. Todo esto fue como un desahogo amistoso del Nuncio que colaboró entre bastidores a ese magistral documento: La Iglesia y la comunidad política del 23 de enero de 1973. El Nuncio dijo entre otras cosas lo siguiente: "Ahora es fácil leer u oir en las páginas de la prensa o por voces más autorizadas afirmaciones de que el Nuncio hace politica, que los obispos se meten en política etc.... Este tipo de frases, aunque deben obligarnos a reexaminar nuestras conductas, ya que nadie está exento de posibles extralimitaciones en su función, provienen en la mayoría de los casos de un inexacto conocimiento sobre cuál sea la misión de la Iglesia y cuáles nuestros reales objetivos al realizarla" ${ }^{53}$. Algo parecido está pasando con las críticas sobre el tercer capítulo de la LEF.

Estos datos pueden ponernos en el ambiente o contexto de

53. Ecclesia 1584 (1972) 415-420; Cf. N. Jubany, "La función profética de la Iglesia en los Concordatos". La revisión del Concordato español: Ecclesia 1573 (1972) 19-36; L. ECHEVERRIA, H. WAGNON, etc., La Institución concordataria en la actualidad. Trabajos de la XIII Semana de Derecho Canónico (Salamanca 1971). 
las observaciones siguientes: algunos obispos aprueban plenamente los cánones sobre la Iglesia y la sociedad humana, otros ponen enmiendas y no faltan quienes exigen una profunda y total transformación.

Una Conferencia Episcopal manifiesta que el capítulo $3 .^{\circ} \mathrm{sa}$ pit triumphalismum, mientras que otra lo considera perfecto y como buen conjunto de principios para renovar el Derecho Público Eclesiástico.

Algunos obispos y bastantes teólogos reprueban la indole política e insisten en la misión profética de la Iglesia, otros consideran aún insuficientes los cánones sobre las relaciones con otras comunidades políticas, religiosas, cristianas o no cristianas ${ }^{54}$.

Los principios establecidos en el Concilio Vaticano II y recogidos en la LEF tienen en cuenta la historia del pasado y del presente para lograr en el futuro un entendimiento justo y equilibrado con las demás sociedades políticas y religiosas a fin de garantizar la libertad de la Iglesia católica con su carácter supra-nacinoal y universal en el campo del Derecho Internacional Público y del ecumenismo. Se están buscando nuevos caminos en los que hay que tener en cuenta la doctrina del Magisterio y los condicionamientos diplomáticos de la praxis concordataria para que la Iglesia cumpla con su misión religiosa y colabore para el bien común procurando la paz y la justicia entre todos los hombres.

Los Estados se declaran autónomos y soberanos con derechos a regular y proteger el ejercicio de las libertades polfticas entremezcladas no pocas veces con las religiosas. Sobre esto hay abundante bibliografía.

Entre las críticas más adversas a la LEF y en especial al capítulo tercero, está la de Giuseppe Alberigo: "La LEF se convierie en una ininterrupida reivindicación de ventajas, privilegios o, en el mejor de los casos derechos a favor de la Iglesia, y deja ver, en cierto sentido el verdadero significado de la LEF: la reafirmación de la Iglesia como potencia entre potencias, cuyos fines espirituales no le impiden, sino más bien revisten de sacralidad, de toda serie de privilegios y derechos ahí afirmados" ${ }^{55}$. El mismo autor actúa en coro contestatario con algunos de los teólogos y juristas centro-

54. Communicationes 4 (1972) 157-159.

55. G. Alberigo, “¿Una Const. para la Igl.” ...10. 
europeos, que protestaron enérgica y orquestadamente en 1971 contra la LEF; en menor número y con más cordura, siguen discutiendo sobre la LEF y lanzando de cuando en cuando manifiestos hostiles al proyecto divulgado. Quieren someter el esquema de la LEF a una discusión histórica y técnica, como de hecho han procurado hacerlo en un voluminoso estudio, donde más que los argumentos brillan los autores: P. C. Bori, B. Calati, P. G. Gamaini, M. D. Chenu, F. Giusberti, A. Ippoliti, L. Martini, J. Neumann, O. Nicco'i, V. Onida, R. Panikkar, P. Prodi y B. Ulinich, entre los que figura, según se hizo notar, G. Alberigo. Para él, resulta reprobable hasta la misma técnica constitucional de las democracias cristianas y liberales. "La misma LEF es un producto de la hegemonía ejercida también en esta ocasión, con efectos siempre más funestos, por el mismo cristianismo occidental y euroamericano. El mito del Estado constitucional es uno de los productos de la cultura política de este área dirigida, sobre todo en los decenios de 1930 a 1950, a la búsqueda de las garantías adecuadas contra la amenaza de los regímenes autoritarios surgidos de su mismo seno. Las tradiciones de las áreas orientales, africanas, fatinoamericanas son del todo extrañas a esta experiencia" ${ }^{56}$. Se ha subrayado lo de latinoamericanas, porque en esto por lo menos está equivocado G. Alberigo, sea por desconocer la historia documentada de esos países o porque ni siquiera las ha visitado. Quienes hemos dejado un retazo de más de una década de vida en las repúblicas hispanoamericanas, podemos dar fe por experiencias personales de que hay constituciones democráticas y hasta dictaduras totalitarias como en Cuba. Tampoco se puede desconocer la incorporación de los países africanos a la civilización occidental mediante la técnica constitucional y democrática, que se está poniendo en práctica en algunas naciones orientales, como Filipinas y el Japón, a pesar de sus tradiciones autóctonas.

La Iglesia no puede estar al margen del progreso jurídico del mundo y de la cultura. Para solucionar la problemática del binomio Iglesia-Estado es necesario concertar acuerdos, incluso con países comunistas y árabes, regímenes autoritarios o dictatoriales. Debiera precisarse en la LEF: ¿a quién compete actuar en los órganos in-

56. "Excursus: Il contesto ecclesiale della LEF": Leg. e Vang. 41-42 (Discussione su una legge fondamentale per la Chiesa). 
ternacionales? ¿Deben hacerlo los Nuncios ante los Estados, o las Conferencias Episcopales? ¿Conviene que actúe el Secretario de Estado y los Legados Pontificios en nombre de la Santa Sede? La respuesta sería fácil de dar en teoría, aunque en la práctica, la Curia Romana suele utilizar los medios lícitos más oportunos de acuerdo con las complicaciones eventuales para llegar a tratados concordatarios o interconfesionales salvando su independencia y libertad (con algunas limitaciones a veces).

\section{CONCLUSIONES}

De lo anteriormente expuesto sobre los antecedentes de la LEF, su evolución histórica, contenido, observaciones y críticas formuladas, se deduce que la Comisión Pontificia tiene bastante material recogido a su disposición para perfeccionar el proyecto. Tiene que ir despacio, reflexionando sobre lo que ha de ser definitivamente retenido o desechado. Algunos canonistas se han abstenido de hacer comentarios en público, porque lo consideran oportuno, hasta que no se publique oficialmente el proyecto, mientras que otros han creído un deber de conciencia crear opinión pública en contra o en favor de la LEF. Es digna de alabanza la actitud de algunos hermanos separados como H. Dombois (luterano) y G. R. Dunstan (anglicano) por su colaboración con tesón y entusiasmo en favor de la LEF para que sirva de vínculo de unión. Hay observaciones serias y oportunas de las Iglesias evangélicas-protestantes principalmente sobre el Primado del Papa, su infalibilidad pontificia y centralismo romano, porque reconocen un Primado de honor y algunos principios fundamentales comunes sobre la jerarquía. En conjunto son más abundantes las observaciones de origen oriental, 'hasta el punto de que además de la LEF, común para toda la lglesia, subsistirán al menos dos códigos: uno latino y otro oriental. No se descarta la posibilidad de otros códigos para Iglesias particulares. El peligro de latinización es más bien aparente que real, porque está desapareciendo el latín de las liturgias nacionales, dando paso a lenguas vernáculas. En la redacción han colaborado muchos orientales, especialmente I. Ziadé, obispo maronita de Beirut y miembro de la Comisión especial. A su lado han trabajado fraternalmente y con buena armonía Patriarcas, obispos, sacerdotes, religiosos y laicos del oriente cristiano ${ }^{57}$.

57. Communicationes 3 (1971) 179-180; Cf. I. ZuzEk, "Un código pa- 
Con todo el material reunido de las distintas aportaciones y tendencias dentro de la Iglesia, no sólo es posible sino necesaria y urgente la LEF para tener un compendio legal o una especie de constitución jurídica, donde aparezca una idea o esbozo bastante completo eclesiológica y escatológicamente de lo que es y debe ser la Iglesia, sabiendo de antemano que durante el peregrinar terreno nunca nos será dado tenerlo con pienitud. La lectura de la LEF no proporcionará una imagen genuina del pueblo de Dios, tal como se pretende en teoría, sino cómo hay que vivir en la práctica y con espíritu cristiano los auténticos ideales de la nueva alianza pascual.

Tratar de dar respuesta satisfactoria a todas las observaciones es algo muy difícil, ni se puede dar cabida en una LEF a todas las sugerencias formuladas; a la Comisión Pontificia corresponde admitir las pertinentes y proponer su trabajo a la consideración del Romano Pontífice y de los demás obispos, que han dado ya mayoritariamente su voto afirmativo a la LEF con bastantes juxta modum expresando su opinión y el sentir del pueblo de Dios. No hace falta tener mucha cultura canónica para advertir que algunas observaciones no tienen razón de ser y se contrarrestan o complementan con otras.

Tanto la LEF, como el nuevo Derecho canónico, tiene sus elementos humanos divinos o naturales y una orientación pastoralista para configurar las estructuras de la Iglesia según la Constitución teológica Lumen gentium, presentando sus raíces sacramentales y su carácter cristocéntrico con formas institucionalizadas. La actividad de la jerarquía tendrá un procedimiento técnico y jurídico más adecuado con la LEF para cumplir sus funciones de enseñar, santificar y regir el pueblo de Dios. Mientras esto se hace realidad, se vivirá en una etapa de transición, solucionando con las antiguas normas y con leyes provisionales algunos de los problemas que plantea el ordenamiento de la conducta de la Iglesia ${ }^{58}$.

En la LEF se establece una Teología del Derecho presentando los principios de una verticalidad jerárquica hacia el Vicario de

ra las Iglesias ortodoxas": Concilium 48 (1969) 298-307; N.N. AFANASIEv, "The Canons of the Church: Changeable or Unchangeable": Si. Vladimir's Seminary Quarterly 2 (1967) 54-58.

58. P. Huizing, "Reflexiones sobre la revisión del Código de Derecho Canónico": Concilium 73 (1972) 390-401. 
Cristo en la tierra y los delineamientos de una horizontalidad fraterna con un jus caritatis que nos vincula más estrechamente con los demás cristianos.

Una de las mayores dificultades con que tropieza la jerarquización de normas, donde aparezca claramente la diferencia entre leyes canónicas fundamentales y leyes ordinarias, es el principio teológico y jurídico: prima sedes a nemine judicatur. Para solucionar este escollo hay que distinguir entre normas jurídicas y actos de Magisterio, entre el contenido teológico del Primado Romano y las distintas formas históricas de su ejercicio. Esta distinción no ha tenido aún acogida favorable en el proyecto por las dificultades que hay contra el historicismo no siempre rectamente interpretado. Mons. Onclin, haciéndose eco de esta problemática, expone que se ha discutido de natura theologica vel juridica huius Legis y se ha llegado a la conclusión de que contiene principios teológicos sobre la estructura eclesiástica y las normas jurídicas fundamentales para todos los fieles, aunque su valor constitucional o fundamental no ha sido aún determinado. Propone que esto se haga en el proemio o en normas finales adicionales ${ }^{59}$.

Tratando de la jerarquía de fuentes, José María Ribas distingue entre el contenido teológico del Primado Pontificio (entrevisto por el Concilio de Calcedonia, definido por el Concilio de Florencia, explicitado dogmáticamente por el Concilio Vaticano I y reasumido por el Concilio Vaticano II) y la forma en que este Primado se ejerza en cada momento histórico. Luego hace la siguiente sugerencia: "Parece conveniente que la futura LEF se halle en la cúspide del sistema de fuentes normativas del ordenamiento canónico, de tal modo que toda norma canónica, que no fuera congruente con la LEF careciese de toda fuerza jurídica, en lo que se opusiese a la LEF, aun cuando hubiese emanado del Romano Pontífice. Esto no constituiría una negación o lesión del contenido teológico del Primado Pontificio, sino una forma histórica de su ejercicio. Si se llegase a esta solución, sería preciso que el Romano Pontífice, precisamente en virtud de su plenitudo potestatis de que goza, autoordenase su actividad en el sentido de que decidiese que sus leyes serían nulas si no fuesen congruentes con la LEF" ${ }^{60}$. Esto, que po-

59. W. ONCLIN, Relatio super priore schem... 61-123.

60. J.M. RIBAs, "La jerarquía de fuentes en el ordenamiento canó- 
dría resultar hoy novedoso, tiene sus antecedentes con menor amplitud en el Código de Derecho Canónico, al prescribirse en determinados supuestos, por ejemplo, el modo de la promulgación de las leyes pontificias para ser válidas o tener vigencia (c. 9) y la necesidad de una expresa cláusula derogatoria para la validez de ciertos rescriptos, cuyo valor es distinto según contengan o no la cláusula motu proprio (cc. 45-46). Tanto la elaboración de la LEF como su promulgación y posible reforma, debe hacerse por órganos especiales y mediante procedimiento peculiar claramente establecido en el proyecto para lograr una mayor seguridad jurídica. Debería establecerse también bajo qué presupuestos o condicionamientos puede y debe ser revisada la LEF, sin descartar la posibilidad de actuar discrecionalmente la Autoridad Suprema, el Romano Pontífice, en casos excepcionales.

En la LEF aparecerá una mayor coherencia entre el elemento humano y el divino con un jus commune para la Iglesia latina y la oriental, abriendo nuevos cauces de viabilidad para establecer relaciones entre el pueblo de Dios y las demás sociedades políticas $y$ religiosas ${ }^{61}$.

\section{P. Fernando Campo}

nico": Jus Canonicum 26 (1973) 308-310. Este autor propone de jure condendo la siguiente jerarquía de fuentes, de mayor a menor rango: 1) La Constitución. 2) Las leyes normativas ordinarias. 3) Las normas de administración eclesiásticas (reglamentos, estatutos, etc.). 4) Negocios normativos. 5) La costumbre.

61. J.A. Souto Notas para una interpretación actual del Derecho Canónico (Pamplona 1973) 32-36. Estando en la imprenta este trabajo, en la revista Communicationes 5 (1973) 196-216, apareció la información oficial de los trabajos de la comisión especial de la LEF, que cuenta con 13 nuevos miembros y se ha reunido en sesión los días 20 al 23 de noviembre de 1972 para estudiar las observaciones formuladas por los obispos. Algunos consuitores han presentado sugerencias y mociones oportunas e interesantes, que han sido aprobadas por la comisión y no aparecen en nuestro estudio. 